\title{
Pengaruh Pemberian Natrium Bikarbonat terhadap Kelelahan dan Nyeri Otot setelah Melakukan Treadmill
}

\section{(The Effect of Sodium Bicarbonate Ingestion on Fatigue and Mucle Pain after Treadmill Exercise)}

\author{
Fath Arina Fahma, Cholis Abrori, Hairrudin \\ Fakultas Kedokteran Universitas Jember \\ Jl. Kalimantan 37 Kampus Tegal Boto Jember 68121 \\ e-mail: cholisabrori.fk@unej.ac.id
}

\begin{abstract}
Treadmill is a physical exercise that caused a metabolic transition from aerobic into anaerobic. The aim of this study was to determine the effect of sodium bicarbonate to reduce fatigue and muscle pain after treadmill. This study used a time-series design with 20 selected samples from undergraduate student population of the Faculty of Medicine, Jember University. Samples consumed $100 \mathrm{mg} / \mathrm{kgBW} \mathrm{NaCl}$ (placebo) and $\mathrm{NaHCO}_{3} 300 \mathrm{mg} / \mathrm{kgBW}$ then perform a treadmil protocol until it reached maximum muscle fatigue. The results showed that the average treadmill of the treatment group $(778,1 \pm 121,21$ seconds) was longer than control group $(717,7 \pm 93,02$ seconds). The intensity of acute pain as measured by VAS (Visual Analog Scale) treatment group was lower $(44,7 \pm 22,47$ units) than control $(55,4 \pm 19,97$ units). So this study inferred that $\mathrm{NaHCO}_{3}$ can reduce fatigue and acute pain intensity after treadmill.
\end{abstract}

Keywords: treadmill, sodium bicarbonate, fatigue, muscle pain

\begin{abstract}
Abstrak
Treadmill merupakan salah satu bentuk latihan fisik yang menyebabkan seseorang mengalami transisi penggunaan energi dari proses metabolisme aerobik menuju metabolisme anaerobik. Tujuan dari penelitian ini adalah untuk mengetahui pengaruh pemberian natrium bikarbonat terhadap berkurangnya kelelahan dan nyeri otot setelah melakukan treadmill. Penelitian ini menggunakan rancangan eksperimental seri dengan sampel 20 orang yang dipilih dari populasi mahasiswa tingkat sarjana Fakultas Kedokteran Universitas Jember. Sampel mengkonsumsi $\mathrm{NaCl} 100 \mathrm{mg} / \mathrm{kgBB}$ (plasebo) dan $\mathrm{NaHCO}_{3} 300 \mathrm{mg} / \mathrm{kgBB}$ kemudian melakukan treadmill hingga mencapai kelelahan otot maksimal. Hasil penelitian didapatkan lama treadmill rata-rata kelompok perlakuan $(778,1 \pm 121,21$ detik) lebih lama dibanding kontrol kelompok kontrol $(717,7 \pm 93,02$ detik). Intensitas nyeri sesaat yang diukur dengan VAS (Visual Analog Scale) kelompok perlakuan lebih rendah $(44,7 \pm 22,47$ satuan) dibanding kontrol (55,4 $\pm 19,97$ satuan). Sehingga disimpulkan $\mathrm{NaHCO}_{3}$ dapat mengurangi kelelahan dan intensitas nyeri sesaat setelah treadmill.
\end{abstract}

Kata kunci: treadmill, natrium bikarbonat, kelelahan, nyeri

\section{Pendahuluan}

Treadmill merupakan salah satu bentuk latihan fisik yang menyebabkan seseorang mengalami transisi penggunaan energi dari proses metabolisme aerobik menuju metabolisme anaerobik. Terdapat tiga fase metabolisme yang terjadi dengan meningkatnya beban treadmill. Fase pertama yaitu fase 
aerobik, kedua yaitu fase transisi aerobik menuju anaerobik, dan ketiga yaitu fase anaerobik. Beberapa teori menyebutkan bahwa metabolisme anaerobik akan menghasilkan akumulasi asam laktat dan dapat menyebabkan kelelahan dan nyeri otot [1,2].

Kelelahan otot pada manusia dapat ditandai dengan penurunan gerakan volunter dan pengurangan fungsi otot yang merupakan penghalang selama latihan. Mekanisme timbulnya kelelahan otot ini dapat menginduksi perasaan nyeri. Pada umumnya, nyeri ini timbul setelah latihan dan mencapai puncak pada 24 sampai 48 jam setelahnya [3]. Orang-orang yang tidak terlatih memiliki kecenderungan kelelahan dan nyeri otot lebih tinggi dibandingkan dengan orang yang terlatih seperti atlet. Hal ini terjadi karena metabolisme para atlet didominasi oleh metabolisme aerobik sehingga akumulasi asam laktat lebih sedikit. Selain itu, tubuh mereka dapat melakukan adaptasi dengan cara meningkatkan rasio oksigen tertinggi yang dapat diambil oleh tubuh atau $\mathrm{VO}_{2} \max$ dan aktivitas enzim pengubah laktat seperti laktat dehidrogenase yang akan menurunkan kadar asam laktat dalam darah $[4,5]$.

Pengurangan asam laktat dari dalam tubuh dapat dilakukan dengan dua cara yaitu, pembuangan melalui keringat maupun urin dan pengubahan asam laktat menjadi senyawa lain. Pengubahan asam laktat menjadi senyawa lain memegang persentase terbesar untuk mengurangi nyeri otot dibanding dengan pembuangan [6]. Secara fisiologis, akumulasi asam laktat sebagai akibat dari latihan intensitas tinggi akan dinetralkan oleh beberapa sistem penyangga dalam tubuh. Ketika kapasitas penyangga di intraseluler terlampaui, asam laktat akan berdifusi ke dalam darah. Pada saat itu, mekanisme penyangga ekstraseluler akan dirangsang [7]. Salah satu sistem penyangga yang memiliki peran utama dalam menetralkan asam di ekstraseluler yaitu sistem bikarbonat $\left(\mathrm{HCO}_{3}{ }^{-} / \mathrm{H}_{2} \mathrm{CO}_{3}\right)$. Sistem ini memberikan kontribusi $\pm 86 \%$ dari total kapasitas penyangga $[8,9]$.

Natrium bikarbonat, dengan rumus kimia $\mathrm{NaHCO}_{3}$ dapat berfungsi sebagai senyawa penyangga dari luar tubuh. Mekanisme utama dari $\mathrm{NaHCO}_{3}$ yaitu menambah bioavailabilitas $\left[\mathrm{HCO}_{3}-\right]$ yang akan bergabung dengan $\mathrm{H}^{+}$untuk membentuk asam karbonat $\left(\mathrm{H}_{2} \mathrm{CO}_{3}\right)$ kemudian secara reversibel oleh enzim karbonat anhidrase (CA) diubah menjadi $\mathrm{H}_{2} \mathrm{O}$ dan $\mathrm{CO}_{2}$ [10]. Maka perlu dilakukan pengujian efek pemberian natrium bikarbonat (dalam bentuk larutan) terhadap kelelahan dan nyeri otot setelah melakukan treadmill sehingga dapat meningkatkan ambang waktu kelelahan serta lama latihan fisik pada orang-orang tidak terlatih.

\section{Metode Penelitian}

Penelitian ini menggunakan jenis quasi eksperimental dengan rancangan eksperimental seri. Penelitian dilakukan di Laboratorium Farmakologi dan Fisiologi Fakultas Kedokteran Universitas Jember dengan menggunakan data primer berupa lembar observasi. Jumlah sukarelawan pada penelitian ini adalah 20 orang dari populasi mahasiswa tingkat sarjana Fakultas Kedokteran Universitas Jember. Tiap subjek menjadi kontrol bagi dirinya sendiri sehingga besar sampel pada penelitian ini adalah 40 sampel.

Beberapa kriteria inklusi dari penelitian ini, meliputi laki-laki usia $21,4 \pm 4,8$ tahun; BMI 18,5 $24,9 \mathrm{~kg} / \mathrm{m}^{2}$; tekanan darah tidak lebih dari 140/90 $\mathrm{mmHg}$; tergolong dalam orang tidak terlatih (ratarata latihan fisik dalam satu minggu $\leq 3$ jam). Sedangkan kriteria eksklusi dari penelitian ini meliputi: memiliki riwayat penyakit kardiovaskuler, paru dan ginjal; melakukan latihan fisik diluar penelitian, mengkonsumsi minuman berenergi atau bahan makanan dan minuman yang mengandung kafein serta stimulan lain selama 1 minggu sebelum perlakuan sampai pengukuran terakhir dilakukan.

Seluruh sukarelawan masuk ke dalam kelompok kontrol yang mengkonsumsi natrium klorida $100 \mathrm{mg} / \mathrm{kgBB}$. Setelah periode washing out selama 7 hari, seluruh sukarelawan berperan sebagai kelompok perlakuan dengan mengkonsumsi natrium bikarbonat $300 \mathrm{mg} / \mathrm{kgBB}$. Kedua bahan tersebut dilarutkan ke dalam 4 $\mathrm{mL} / \mathrm{kgBB}$ air dan $1 \mathrm{~mL} / \mathrm{kgBB}$ sirup jeruk bebas gula. Perlakuan ini dilakukan 60 menit sebelum memulai protokol treadmill [4] sebagai berikut

Tabel 1. Protokol Treadmill

\begin{tabular}{|c|c|c|}
\hline $\begin{array}{c}\text { Waktu } \\
\text { (menit) }\end{array}$ & $\begin{array}{c}\text { Kecepatan } \\
\text { (mili/jam) }\end{array}$ & $\begin{array}{c}\text { Kemiringan } \\
(\%)\end{array}$ \\
\hline 0 & 4,8 & 0 \\
\hline 3 & 5,6 & 2 \\
\hline 6 & 7,2 & 3 \\
\hline 9 & 8,8 & 5 \\
\hline 12 & 11,3 & 8 \\
\hline 15 & 12,8 & 10 \\
\hline 18 & 12,8 & 12 \\
\hline
\end{tabular}

Lama waktu pada saat sukarelawan tidak 
dapat melanjutkan protokol treadmill dihitung. Kemudian sukarelawan mengisi kuesioner intensitas nyeri otot dengan VAS (Visual Analog Scale) yang meliputi intensitas nyeri sesaat, 24 jam, 48 jam, dan 72 jam setelah melakukan treadmill. Hasil penelitian ini dianalisis menggunakan uji statistik uji T (T-paired test) dengan pengolahan data menggunakan bantuan perangkat lunak SPSS 21.0.

\section{Hasil}

Pada penelitian ini didapatkan hasil sebagai berikut:

Tabel 2. Rata-Rata Lama Treadmill

\begin{tabular}{|l|c|}
\hline Kelompok & Rata-rata Lama Treadmill \\
\hline Kontrol & $717,7 \pm 93,02$ \\
\hline Perlakuan & $778,1 \pm 121,21$ \\
\hline
\end{tabular}

Berdasarkan data pada Tabel 1 dapat disimpulkan bahwa sukarelawan pada kelompok perlakuan dapat melakukan treadmill lebih lama dibandingkan kelompok kontrol $(p=0,001)$. Pada waktu tersebut didapatkan nilai rata-rata denyut nadi kelompok kontrol 164,8 denyut/menit, sedangkan kelompok perlakuan 169,3 denyut/menit.

Tabel 3. Rata-Rata Intensitas Nyeri Otot

\begin{tabular}{|l|c|c|c|}
\hline \multicolumn{1}{|c|}{ Waktu } & Kontrol & Perlakuan & $\mathrm{p}$ \\
\hline $\begin{array}{l}\text { Sesaat } \\
\text { setelah } \\
\text { treadmill }\end{array}$ & $55,4 \pm 19,97$ & $44,7 \pm 22,47$ & 0,024 \\
\hline $\begin{array}{l}24 \text { jam } \\
\text { setelah } \\
\text { treadmill }\end{array}$ & $4,9 \pm 14,42$ & $4,3 \pm 9,36$ & 0,5 \\
\hline $\begin{array}{l}48 \text { jam } \\
\text { setelah } \\
\text { treadmill }\end{array}$ & 0 & 0 & 1 \\
\hline $\begin{array}{l}72 \text { jam } \\
\text { setelah } \\
\text { treadmill }\end{array}$ & 0 & 0 & 1 \\
\hline
\end{tabular}

Tabel 3 menunjukkan bahwa kelompok perlakuan memiliki intensitas nyeri sesaat yang lebih rendah dibandingkan kelompok kontrol. Sedangkan pemeriksaan pada 24 jam, 48 jam, dan 72 jam setelah treadmill antara kelompok perlakuan dan kelompok kontrol tidak terdapat perbedaan yang signifikan.

\section{Pembahasan}

Kelompok kontrol memiliki rata-rata lama treadmill 717,7 $\pm 93,02$ detik dengan seliisih 60,4 detik jika dibandingkan rata-rata kelompok perlakuan $(778,1 \pm 121,21$ detik). Perbedaan antara kelompok perlakuan dan kelompok kontrol menghasilkan nilai $p$ yang signifikan $(p<0,01)$. Rata-rata denyut nadi pada kelompok kontrol (164,8 detik) dan kelompok perlakuan $(169,3$ detik), keduanya menunjukkan bahwa sukarelawan mencapai $80-90 \%$ dari denyut nadi maksimal atau termasuk dalam intensitas latihan submaksimal [11].

Latihan fisik yang dilakukan dengan intensitas mendekati maksimal (submaksimal) menyebabkan terjadinya pergeseran sistem energi aerobik ke sistem energi anaerobik, kondisi ini akan dapat menyebabkan peningkatan kadar asam laktat darah darah [12,13]. Menurut Meceir et al. [13], dengan meningkatnya aktivitas fisik, maka kebutuhan energi dan kebutuhan akan oksigen juga akan meningkat. Pasokan kebutuhan oksigen dapat ditambah dengan meningkatkan respirasi paru dan denyut jantung. Ketika hal tersebut tidak mencukupi, maka terjadi metabolisme anaerobik sebagai kompensasi terhadap pemenuhan energi.

Tingginya konsentrasi kadar asam laktat menurunkan kekuatan kontraksi otot dengan menurunkan daya ikat ion $\mathrm{Ca}^{2+}$ pada troponin dan meningkatnya daya ikat retikulum sarkoplasmik terhadap ion $\mathrm{Ca}^{2+}$. Kedua mekanisme ini akan menurunkan jumlah ion $\mathrm{Ca}^{2+}$ yang diikat pada troponin selama proses kontraksi otot sehingga akan sangat merugikan aktivitas fisik yang menggunakan kinerja tinggi [2]. Kadar asam laktat yang tinggi juga akan berpengaruh terhadap produksi ATP, sebab enzim yang berperan terhadap proses pembentukan ATP melalui glikolisis akan terhambat oleh keasaman dan akumulasi asam laktat. Enzim tersebut yaitu fosfofruktokinase yang bertugas mengubah fruktosa 6 fosfat menjadi fruktosa 1,6 difosfat [2].

Intensitas nyeri otot diukur sebanyak 4 kali yaitu sesaat setelah treadmill, 24 jam, 48 jam dan 72 jam setelah treadmill. Setelah data dikumpulkan ternyata hanya 2 data pengukuran yang dapat dibandingkan, yaitu data intensitas nyeri sesaat setelah treadmill dan nyeri tunda pada 24 jam setelah treadmill. Pada 48 dan 72 jam setelah treadmill, semua sukarelawan pada kelompok kontrol maupun perlakuan sudah tidak merasakan nyeri otot.

Sesuai dengan Visual Analog Scale 
(VAS), nilai rata-rata nyeri otot sesaat setelah treadmill pada kelompok kontrol yaitu $55,4 \pm 19,97$ satuan, sedangkan kelompok perlakuan yaitu $44,7 \pm 22,47$ satuan. Kedua kelompok tersebut memiliki perbedaan yang signifikan dengan nilai $p$ sebesar $0,024 \quad(p<0,05)$. Konsumsi larutan natrium bikarbonat $300 \mathrm{mg} / \mathrm{kgBB}$ dapat mengurangi nyeri otot. Hal ini disebabkan ujung saraf nyeri yang tersensitisasi oleh akumulasi ion hidrogen lebih sedikit [14].

Perasaan nyeri sesaat setelah treadmill juga dapat diakibatkan lisisnya membran sel otot oleh radikal bebas khususnya ROS (reactive oxygen spesies). Radikal bebas pada saat latihan terbentuk dari berbagai proses seperti peroksidasi lemak, metabolisme aerobik, reaksi autooksidasi hemoglobin dan mioglobin, iskemia jaringan, mekanisme peradangan, dan lain lain. Selain itu, peningkatan asam laktat akan merubah senyawa oksigen reaktif menjadi lebih reaktif. Kadar laktat yang tinggi menurunkan $\mathrm{pH}$ sehingga merangsang prostaglandin dan leukotrien membentuk ROS. Penurunan $\mathrm{pH}$ menyebabkan tingkat keasaman meningkat yang disebut sebagai asidosis. Keadaan asidosis akan merubah radikal bebas yang toksik lemah menjadi radikal bebas toksik kuat melalui reaksi

$$
\mathrm{O}_{2}^{-}+\mathrm{H}^{+} \text {à } \mathrm{OOH}
$$

Sumber $\mathrm{O}_{2}$ berasal dari peningkatan konsumsi oksigen dan sumber $\mathrm{H}^{+}$berasal dari asam laktat. Keadan asidosis dimana $\mathrm{pH}$ kurang dari normal menyebabkan terganggunya kerja enzim termasuk enzim antioksidan. Semakin besar pergeseran $\mathrm{pH}$ dari $\mathrm{pH}$ normal, maka semakin banyak pula enzim yang tidak aktif dan radikal bebas yang semakin reaktif sehingga menyebabkan lisisnya membran sel otot [15].

Nilai rata-rata intensitas nyeri otot 24 jam setelah treadmill pada kelompok kontrol yaitu $4,9 \pm 14,42$ satuan sedangkan kelompok perlakuan yaitu $4,3 \pm 9,36$ satuan. Meskipun secara rata-rata pada kelompok perlakuan mengalami penurunan intensitas nyeri otot, namun kedua kelompok tersebut tidak memiliki perbedaan yang signifikan yang ditunjukkan dengan nilai $p$ sebesar $0,5(p>0,05)$.

Teori tentang asam laktat menyebutkan bahwa otot eksentrik akan terus memproduksi asam laktat meskipun aktivitas fisik telah dihentikan sehingga akumulasi asam laktat tersebut dapat menginduksi kerusakan dan nyeri [16]. Meskipun demikian, setiap sukarelawan memiliki kemampuan tersendiri dalam menetralisir asam laktat dalam tubuhnya. Hal ini yang membuat intensitas nyeri tunda sukarelawan berbeda-beda. Adanya perbedaan aktivitas enzim pengubah laktat seperti laktat dehidrogenase yang menyebabkan beragamnya nilai intensitas nyeri tunda [5]. Sehingga dalam pemberian natrium bikarbonat, tidak didapatkan pengaruh yang signifikan pada intensitas nyeri tunda sukarelawan.

Kelemahan dalam penelitian ini yaitu bergantung pada kondisi sukarelawan dimana lama waktu treadmill dan intensitas nyeri otot ditentukan oleh persepsi dan pengalaman dari masing-masing individu sukarelawan. Oleh karena itu, dua sukarelawan yang yang sebenarnya memiliki intensitas kelelahan sama dapat mempersepsikan dengan respon yang berbeda sesuai dengan ketahanan tubuhnya. Begitu juga dengan persepsi nyeri, intensitas nyeri dua sukarelawan yang sebenarnya sama dapat dipersepsikan dengan skala yang berbeda sesuai dengan ambang nyeri masing-masing individu.

\section{Simpulan dan Saran}

Berdasarkan hasil analisis data dan pembahasan yang telah dijabarkan, didapatkan kesimpulan bahwa pemberian natrium bikarbonat memeiliki efek terhadap berkurangnya kelelahan dan nyeri otot sesaat setelah melakukan treadmill. Namun dibutuhkan penelitian lebih lanjut untuk mengetahui patofisiologi natrium bikarbonat menjadikan sukarelawan melakukan treadmill lebih lama dan patofisiologi natrium bikarbonat menjadikan sukarelawan merasakan intensitas nyeri lebih rendah serta diperlukan penelitian lebih lanjut dengan pengukuran lain seperti pengukuran kadar asam laktat yang dapat menggambarkan kelelahan otot dan intensitas nyeri secara laboratoris.

\section{Daftar Pustaka}

[1] Skinner JS, Mclellan TH. The transition from aerobic to anaerobic metabolism. Res $Q$ Exerc Sport. 1980; 51(1): 234-248.

[2] Widiyanto, Hariono A, Tirtawirya D. Karakteristik lactate threshold pada atlet taekwondo Daerah Istimewa Yogyakarta selama kompetisi. Jurnal Penelitian Humaniora FIK Universitas Negeri Yogyakarta. 2014; 19(2): 190-198.

[3] Ishii H, Nishida Y. Effect of lactate accumulation during exercise-induced muscle fatigue on the sensorimotor cortex. J Phys Ther Sci. 2013; 25(12): 1637-1642.

[4] Green JM, Horcsby JH, Pritchett RC, Pritchett K. Lactate threshold comparison in 
anaerobic vs. Aerobic athletesand untrained participants. Int J Exerc Sci. 2014; 7(4): 329338.

[5] Basset DR, Howley ET. Limiting factor for maximum oxygen uptake and determinants of endurance performance. Med Sci Sports Exerc. 2000; 32(1): 70-84.

[6] Bompa OT. Theory and methodology of training. 5th ed Toronto: Mosaic Press; 2009.

[7] Matson LG, Tran ZV. Effect of sodium bicarbonate on anaaerobic performance: a meta-analytic review. Int J Sport Nutr. 1993; 3(1): 2-28.

[8] Adrogue HE, Adrogue HJ. Acid-base physiology. Resp Care. 2001; 46(4): 328341.

[9] Poupin N, Calvez J, Lassale C, Chesneau, Tome D. Impact of the diet on net endogeneous acid production and acid-base balance. Clin Nutr. 2012; 31(3): 313-321.

[10]Higgins MF. The effects of sodium bicarbonate $\left(\mathrm{NahCO}_{3}\right)$ on whole body and isolated skeletal muscle performance [tesis]. Coventry: Coventry University; 2013.
[11]Sukadiyanto. Pengantar teori dan metodologi melatih fisik. Yogyakarta: Pendidikan Kepelatihan Olahraga Fakultas Keolahragaan Universitas Negeri Yogyakarta; 2005.

[12]Jansen $P$. Training lactate pulse rate. Oule Finland: Polar Electro; 1989.

[13]Meceir J, Mercier B, Prefaut C. Blood lactate during the force velocity exercise test. Int $\mathrm{J}$ Sports Med. 1991; 12(1): 17-20.

[14]Shaji JK, Sivaram C, Naqvi W, Natho M. The relationship between time of onset and duration of delayed onset of muscle soreness with the intensity of exercises performed. J Orthop Rehabil. 2015; 1(2): 2-5.

[15]Purnomo Mochammad. Asam laktat dan aktivitas sod eritrosit pada fase pemulihan setelah latihan submaksimal. Jurnal Media IImu Keolahragaan Indonesia. 2011; 1(2): 155-170.

[16]Gulick DT, Kimura IF. Delayed onset muscle soreness: what is it and how do we treat it? J Sport Rehabil. 1996; 5(3): 234-243. 